\title{
ATMOSPHERIC PRESSURE PLASMA CLEANING AND ACTIVATION OF FLOAT SODA-LIME GLASS PRIOR TO LAMINATION PROCESSING
}

\author{
${ }^{1}$ Slavomír SIHELNÍK, ${ }^{1} J a k u b$ KELAR, ${ }^{2}$ Miroslav ZEMÁNEK, ${ }^{3}$ Oliver BEIER, \\ 1'Zlata KELAR TUČEKOVÁ, ${ }^{1}$ Richard KRUMPOLEC, ${ }^{1}$ Monika STUPAVSKÁ, ${ }^{4}$ Jost WITTWER, \\ ${ }^{3}$ Bernd GRÜNLER, ${ }^{3}$ Andreas PFUCH, ${ }^{2}$ Dušan KOVÁČIK, ${ }^{1}$ Mirko ČERNÁK \\ ${ }^{1}$ Masaryk University, Faculty of Science, CEPLANT, Department of Physical Electronics, Brno, \\ Czech Republic, EU, sihelnik@mail.muni.cz \\ ${ }^{2}$ ROPLASS s. r. o., Kamenice, Brno, Czech Republic, EU \\ IINNOVENT e.V. Technology Development Jena, Jena, Germany, EU \\ ${ }^{4}$ Polartherm Flachglas GmbH, Großenhain, Germany, EU
}

https://doi.org/10.37904/nanocon.2019.8769

\begin{abstract}
Precleaning of float glass is an important step in manufacturing processes based on combining its surface with other materials. Cleanness, together with surface roughness and chemical activity affect adhesion properties of the substrate that are crucial for the quality of the final product. Atmospheric pressure plasma pretreatment was studied as a dry alternative to conventional wet cleaning methods of glass, with the aim at industrial requirements. Diffuse coplanar surface barrier discharge (DCSBD) and multi-hollow surface dielectric barrier discharge in air at atmospheric pressure were used on soda-lime glass to prove the applicability of thermally non-equilibrium plasma. Surface analyses by water contact angle measurement, X-ray photoelectron spectroscopy, atomic force microscopy and Fourier-transform infrared spectroscopy were complemented by industrial ball drop and bending tests realized on laminated safety glass. A highly effective and non-invasive surface treatment suitable for large-area processing was achieved with the plasma of DCSBD. Targeting the industrial applications, the DCSBD system was adjusted to the devices to enable contactless and in-line electrode implementation to the manufacturing processes. Thanks to the cooperation with a glass manufacturing company, these DCSBD operating devices proved advancement also under industrial conditions.
\end{abstract}

Keywords: Atmospheric plasma treatment, glass cleaning, laminated safety glass, DCSBD, Multi-hollow SDBD, adhesion improvement

\section{INTRODUCTION}

The main objective of laminated glass is ensuring front-impact crash resistance, which is a valuable property for automotive industry [1], civil engineering or arms industry [2]. The toughness of laminated products is dependent on the adhesion of contact surfaces. This study targets the adhesion improvement of glass surface without side-effects to its internal structure by precleaning and chemical activation [1], [3], [4]. In manufacturing, the float glass typically passes through a washing machine with brushes and conditioned water. Plasma can be considered an attractive tool for dry surface pretreatment of glass before coating with added layers [4], its bonding [1], [2] or laminating [5]. Reduction of power consumption and waste production demand alternatives such as plasma treatment. The use of thermally non-equilibrium plasma generated in air at atmospheric pressure reduces costs for surface treatment of materials like the widely used soda-lime glass (SLG) [6]. In this study, the effect of pretreatment by plasma generated using two different surface dielectric barrier discharges (DBD) was studied with the aim of contactless and in-line electrode implementation under industrial conditions. In previous studies of nonthermal plasma treatment on SLG including e.g. magnetron sputtering [4], or utilization of glide arc [5], plasma jet [1], volume DBD [7] and surface DBD [2], [3], [5], [8] only small 
areas of glass were investigated, whereas in our experiments and industrial trials we were able to treat largearea glass.

\section{EXPERIMENT}

In this study, plasma treatments were accomplished with two different surface dielectric barrier discharge systems operating in ambient air at atmospheric pressure: diffuse coplanar surface barrier discharge (DCSBD) and multi-hollow surface dielectric barrier discharge (MSDBD). The DCSBD plasma unit made by ROPLASS, s. r. o. ( $400 \mathrm{~W}, \mathrm{AC}, 15 \mathrm{kHz}$, amplitude $\sim 10 \mathrm{kV})$ generates $0.3 \mathrm{~mm}$ thin plasma layer with areal dimensions $80 \times 210 \mathrm{~mm}$ [6]. The MSDBD unit made by Kyocera (25-30 W, AC, $27 \mathrm{kHz}$, amplitude $\sim 10 \mathrm{kV}$ ) generates an active plasma area of $18 \times 19 \mathrm{~mm}$. The MSDBD plasma was employed during the plasma treatment procedures from various distances with or without flowing air served as the working gas. The listed values of supplying power for each discharge system resulted in generation of plasma with the same value of power density of $2.5 \mathrm{~W} / \mathrm{cm}^{2}$.

SLG samples from Polartherm-Flachglas $\mathrm{GmbH}$ used for laboratory plasma treatment had a thickness of 2.1 or $2.8 \mathrm{~mm}$ and areal dimensions in the order of centimetres in dependence on the applied surface analytical method for studying the induced surface changes. Industrial conditions were simulated by leaving the samples uncleaned before water contact angle (WCA) measurement and X-ray photoelectron spectroscopy (XPS) analysis. All atomic force microscopy (AFM) roughness measurements, except for one comparative, were realised on samples precleaned in an ultrasonic cleaner (USC) with three liquids: acetone, isopropyl alcohol and double deionised water. Fourier-transform infrared (FTIR) spectroscopy targeted on the evaluation of cleaning effect of plasma treatment was carried out on SLG precleaned in acetone using USC, subsequently intentionally contaminated by $100 \mathrm{~nm}$ layer of stearic acid (SA) deposited in an evaporation chamber. Laminated safety glass examined by mechanical tests were composed of two float SLG of $4 \mathrm{~mm}$ thickness and a polyvinyl butyral (PVB) adhesive film with a thickness of $0.38 \mathrm{~mm}$. Safety glass areal dimensions were in the order of meters, thus exceeding the range of active discharge units. This fact creates a demand for the non-contact leading of DCSBD plasma units implemented by pneumatic bearings or specially designed holder. Large samples for laminated safety glass examined by mechanical tests in Polartherm-Flachglas were precleaned by an in-line washing machine with conditioned water. Further processing of laminated glass included pressing, heating, and maturing in an autoclave. Presence of tin as a manufacturing residual was continuously controlled by various tin side detectors to ensure experimental consistency. The major part of experiments was accomplished on SLG sides without tin content; however, the surface that is bonded by the adhesive film in the lamination process usually contains tin, and it was also examined.

The static WCA measurements analysed with See System by Advex Instruments, s. $r$. o. were performed with $1 \mu \mathrm{l}$ drops of double deionised water. The XPS analysis was realised with an analytic platform ESCALAB 250 $X i$ by Thermo Fisher Scientific using Al Ka source and Rowland circle monochromator. Spectra calibration, processing and fitting routines were completed in Avantage software. An AFM topology analysis with Ntegra Prima by NT-MDT was accomplished on a $5 \times 5 \mu \mathrm{m}$ area in semi-contact mode. The FTIR spectra analysed with Horizon MB software were obtained with $M B 3000$ by $A B B \mathrm{GmbH}$ using $4 \mathrm{~mm}$ aperture. The ball drop testing of laminated glass on Kugelfall $5 S$ by Torgauer Maschinenbau $\mathrm{GmbH}$ employed a $1 \mathrm{~kg}$ iron ball free fall from the height of 4 meters. The bending test evaluated with Glasprüfstand.vi software was accomplished with $Z P M-U$ by ift Rosenheim $\mathrm{GmbH}$ using $\mathrm{G}$ indenter. Both mechanical tests followed the relevant DIN/EN/ISO standards.

\section{RESULTS AND DISCUSSION}

The WCA measurement revealed a significant wettability improvement of SLG surface after short-term exposure to the utilized plasmas. Figure 1 shows the WCA results achieved in experiments on uncleaned 
glass with 1 and $3 \mathrm{~s}$ exposures from distances of $0,0.3,1$ and $3 \mathrm{~mm}$. The average reference value $(26 \pm 1)^{\circ}$ from two sets of samples with comparable contamination was obtained on the sides without tin. Reference WCA measurement on the tin-side resulted in values equal within the range of uncertainty. DCSBD plasma treatment proved the most effective treatment-a $1 \mathrm{~s}$ exposure led to WCA reduction to $(9.5 \pm 0.3)^{\circ}$, which is less than reported in [7] and more than in [3] and [8]. However, $3 \mathrm{~s}$ MSDBD exposure in contact mode (distance $0 \mathrm{~mm}$ ) resulted in the lowest WCA value $(6.3 \pm 1.3)^{\circ}$, which is similar in the range of uncertainty to the result achieved with DCSBD for the same exposure time and also to the value referred to in [8]. Employing noncontact mode of MSDBD leading at the $0.3 \mathrm{~mm}$ distance commonly used for DCSBD [6] resulted in WCA values higher than $10^{\circ}$ without gas flow and $15^{\circ}$ using air as working gas. MSDBD applied at the distance of $1 \mathrm{~mm}$ from samples gives comparable results for both flow modes, while at $3 \mathrm{~mm}$ the use of air induced more significant hydrophilicity improvement. DCSBD plasma treatment showed better uniformity, which is evident from the accuracy of WCA measurement. Implementation of flowing air resulted in higher uncertainties independently on the distance, causing lower homogeneity of treatment effect.

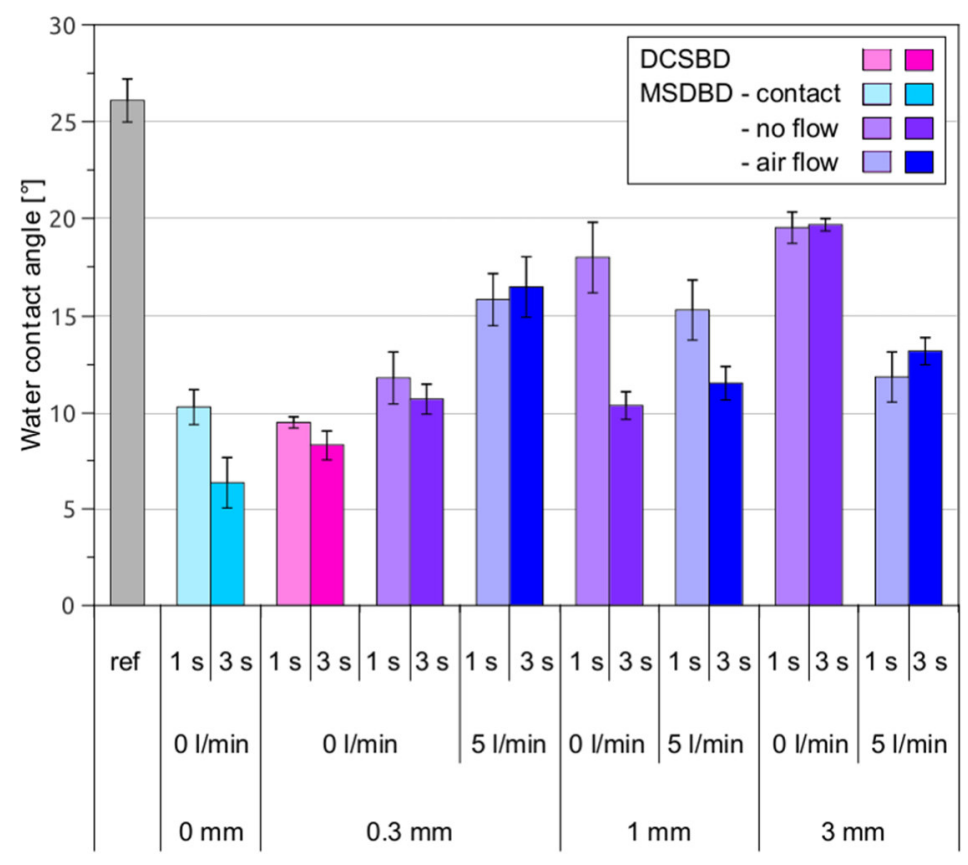

Figure 2 WCA values measured on uncleaned SLG after 1 and $3 \mathrm{~s}$ plasma treatments

The XPS analysis of glass samples exposed to plasma for $3 \mathrm{~s}$ focused on the presence of silicon, carbon and oxygen on the surface. Resulting areas of peaks $\mathrm{Si} 2 \mathrm{p}, \mathrm{C} 1 \mathrm{~s}$ and $\mathrm{O} 1 \mathrm{~s}$ in relative units are shown in comparison to the respective values of WCA in Figure 2. Binding energies in the measured spectra were 102.9, 284.8 and $532.4 \mathrm{eV}$ for silicon, carbon and oxygen peaks, respectively. The presence of silicon in the analysable depth profile $(<10 \mathrm{~nm})$, and its increase can be interpreted as a sign of decontamination of the SLG surface. This cleaning effect was demonstrated for plasma treatments from a distance of $0.3 \mathrm{~mm}$ and less. Carbon content follows two mechanisms: decrease by organic contamination removal and increase by the bonding of carbonyl and carboxyl functional groups. Generally, except for the treatment from $1 \mathrm{~mm}$ distance, a more significant relative decline of carbon content was achieved by MSDBD plasma independently of the employed working gas flow. Oxygen originates in the glass material, in contaminants from water vapour in the air, and also from chemically active functional groups. All investigated plasma treatments induced an increase in oxygen content, which was most significant for exposures from a distance $0.3 \mathrm{~mm}$ and less. Similar silicon, carbon, and oxygen proportional alterations were acquired with plasma jet [1], and DCSBD [3], where high-resolution spectra targeted on binding energies revealed a decrease of $\mathrm{C}-\mathrm{C}$ or $\mathrm{C}-\mathrm{H}$ bonds along with an increase of $\mathrm{C}-\mathrm{O}$ and 
$\mathrm{O}-\mathrm{C}=\mathrm{O}$ bond concentrations. Carbon and oxygen rearrangement caused by chemical activation is reflected in the O/C ratio approaching 1 on an untreated sample. The maximum increase of O/C to 9.1 was achieved by MSDBD in contact mode. DCSBD plasma treatment showed an O/C increase to 4.8 , which was lower than values acquired with MSDBD plasmas applied from the same $0.3 \mathrm{~mm}$ distance independently of the flow mode.

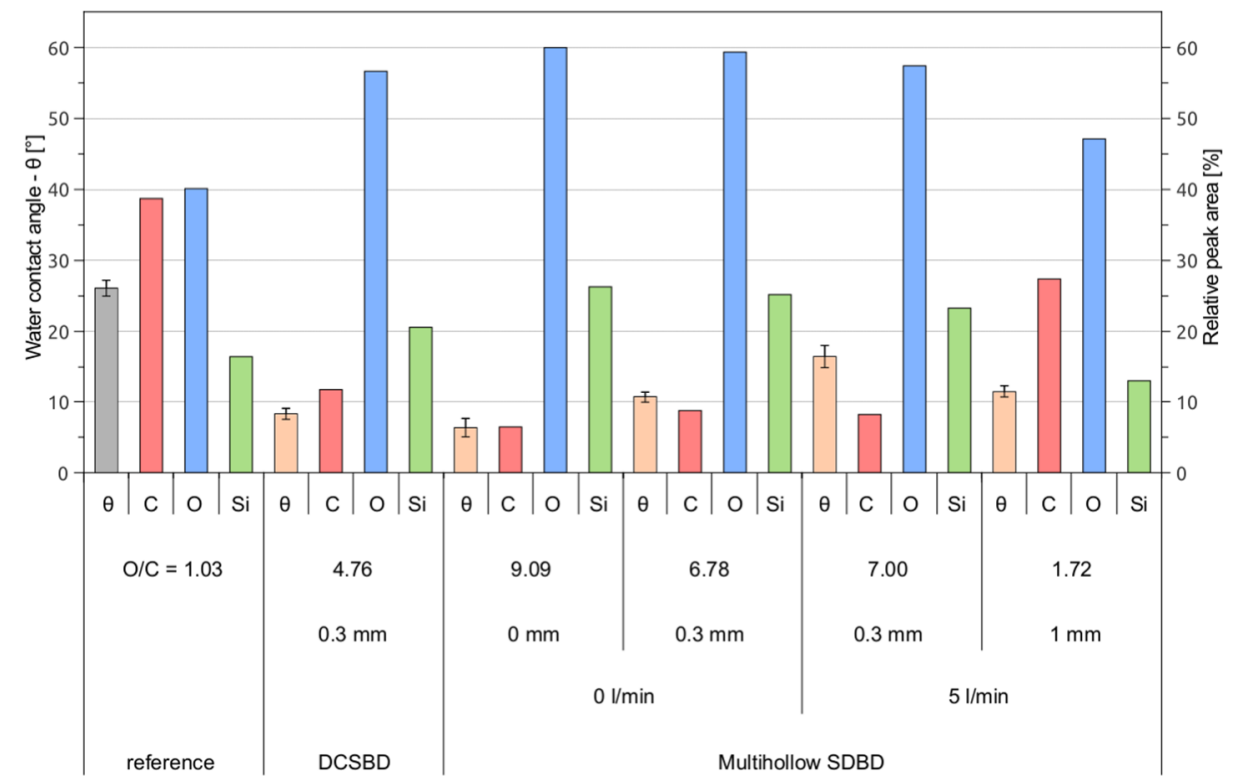

Figure 2 XPS analysis of elemental composition compared with WCA $(\theta)$ decrease on uncleaned SLG after $3 \mathrm{~s}$ plasma treatments

The AFM analysis of surface topology focused on the structural changes after the use of standard wet cleaning methods and investigated plasma techniques. Table 1 lists the root mean square roughness (Sq) and arithmetical mean roughness (Sa). Smoothing of the surface while cleaning with three liquids in a USC was proven by threefold $\mathrm{Sq}$ decrease, which is in agreement with [4]. Further experiments with $3 \mathrm{~s}$ plasma exposures on 3-liquid precleaned SLG revealed significant roughness change induced exclusively by the use of MSDBD in contact mode reflected by Sq doubling. DCSBD and MSDBD in non-contact mode applied for $3 \mathrm{~s}$ showed a harmless effect on the SLG surface confirmed by an unaltered roughness, which was also achieved in previous studies of DCSBD treatment [5], [8], or of volume DBD in helium [7].

Table 1 AFM measurement of Sq and Sa on a $5 \mu \mathrm{m} \times 5 \mu \mathrm{m}$ area of SLG surface

\begin{tabular}{|c|c|c|c|c|}
\hline Sample & $\mathbf{S q}(\mathbf{n m})$ & $\mathbf{u}(\mathbf{S q}) \mathbf{( n m})$ & $\mathbf{S a}(\mathbf{n m})$ & $\mathbf{u}(\mathbf{S a})(\mathbf{n m})$ \\
\hline Uncleaned & 4.4 & \pm 1.6 & 2.3 & \pm 0.4 \\
\hline 3-liquid cleaned, 3 $180 \mathrm{~s}$ & 1.4 & \pm 0.4 & 0.5 & \pm 0.1 \\
\hline DCSBD, 0.3 mm, 3 s & 1.5 & \pm 0.2 & 1.1 & \pm 0.2 \\
\hline MSDBD, 0 I/min, 0 mm, 3 s & 2.8 & \pm 1.6 & 1.4 & \pm 0.6 \\
\hline MSDBD, 0 I/min, 0.3 mm, 3 s & 1.3 & \pm 0.6 & 0.7 & \pm 0.3 \\
\hline MSDBD, 5 I/min, 0.3 mm, 3 s & 1.2 & \pm 0.3 & 0.7 & \pm 0.2 \\
\hline
\end{tabular}

Based on the results presented up to this point, the DCSBD unit was implemented in Airpillow DCSBD-a device for non-contact leading of DCSBD unit at a perfectly accurate distance of $0.3 \mathrm{~mm}$ for large-area treatment. The FTIR spectroscopy measurement on intentionally contaminated SLG samples by SA layer resulted in spectra of absorbed radiation shown in Figure 3. Absorbances at the detected peaks of $\mathrm{CH}_{2}$ band at wavenumbers 
2850 and $2917 \mathrm{~cm}^{-1}$ were gradually decreasing with the extending exposure time by repeated Airpillow DCSBD plasma treatments. This fact indicates surface decontamination, which was almost complete after a total sum exposure of $5 \mathrm{~s}$.

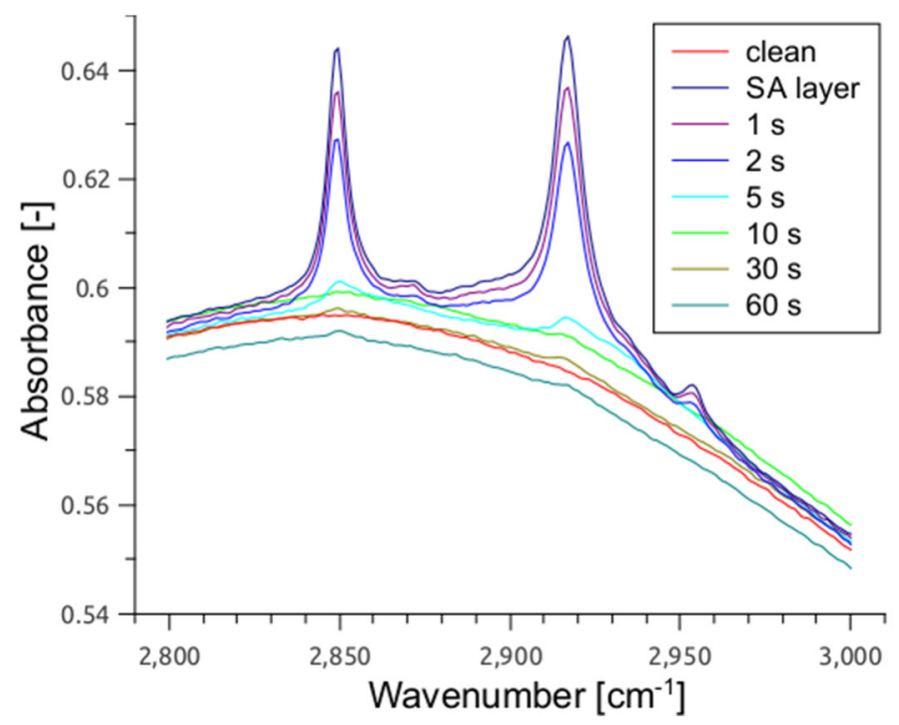

Figure 3 FTIR spectra interpreting SA decomposition from SLG surface

The automatic ball drop test demonstrated a remarkable improvement of laminated safety glass crash resistance, illustrated in Figure 4. The composite of Airpillow DCSBD plasma-treated glass plates with the embedded DCSBD plasma-treated PVB adhesive film succeeded without fractures.

As shown in Table 2, the bending test performed on safety laminated glass confirmed toughness enhancement reached by employing the DCSBD plasma pretreatment. Evaluation of breaking force proved $46 \%$ progress for samples composed of glass treated by Airpillow DCSBD plasma, and $52 \%$ with DCSBD plasma treated PVB adhesive film. A comparable improvement of adhesive strength of a joint composed of DCSBD plasmatreated glass was demonstrated in lap-shear testing on small samples [2].

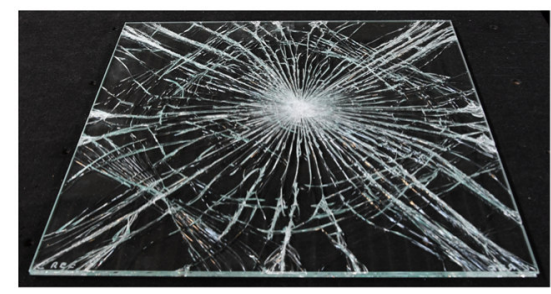

no plasma treatment

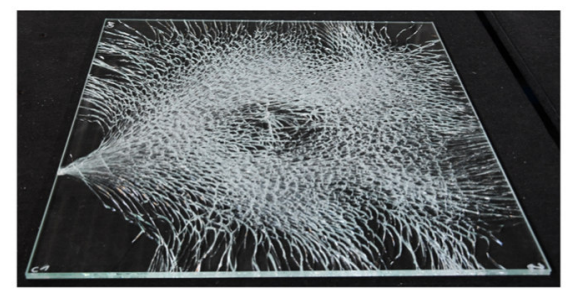

plasma treated glass

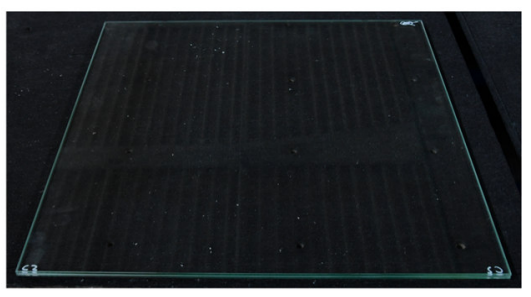

plasma treated glass and PVB film

Figure 4 Photos illustrating the ball drop test results of safety laminated glass made without/with the implementation of DCSBD plasma

Table 2 Breaking force evaluated by a bending test of laminated safety glass made without/with the implementation of DCSBD plasma

\begin{tabular}{|c|c|c|c|}
\hline Glass & PVB film & $F_{\text {MAx }(\mathbf{N})}$ & $\mathbf{u}\left(\mathbf{F}_{\text {MAx }}\right)(\mathbf{n m})$ \\
\hline No treatment & No treatment & 651.1 & \pm 128.5 \\
\hline DCSBD 3 s, $400 \mathrm{~W}, 15 \mathrm{kHz}, 0.3 \mathrm{~mm}$ & No treatment & 949.4 & \pm 104.0 \\
\hline DCSBD 3 s, $400 \mathrm{~W}, 15 \mathrm{kHz}, 0.3 \mathrm{~mm}$ & DCSBD 3 s, $400 \mathrm{~W}, 15 \mathrm{kHz}, 0.3 \mathrm{~mm}$ & 989.0 & \pm 89.3 \\
\hline
\end{tabular}




\section{CONCLUSION}

Surface treatment of SLG by the studied surface DBD plasmas showed a significant wettability improvement attributed to chemical activation by incorporation of oxygen-containing functional groups. Cleaning of organic contamination on the microscopic scale with respect to preservation of SLG structure was demonstrated. The DCSBD plasma unit proved suitable for non-contact leading implementation, which resulted in Airpillow DCSBD development. The mechanical tests of the DCSBD plasma-treated SLG manifested a significant improvement of safety glass strength and suitability of the DCSBD system for fast large-area in-line production in factory conditions.

\section{ACKNOWLEDGEMENTS}

This research has been supported by the projects Alternative methods for processing glass using atmospheric pressure plasma technology, CZ.01.1.02/0.0/0.0/16_053/0007132 funded by the European Regional Development Fund and by the German BMWi under grant No. ZF4028609AG6.

\section{REFERENCES}

[1] LUNDEVALL, Åsa, SUNDBERG, Peter, and MATTSSON, Lars. Improved glass bonding with plasma treatment. Applied Adhesion Science, [online]. 2018. vol. 6, iss. 1, p. 9. [viewed 2019-09-18] Available from: https://doi.org/10.1186/s40563-018-0111-6

[2] BUČEK, Andrej, BRABLEC, Antonín, KOVÁČIK, Dušan, SŤAHEL, Pavel, and ČERNÁK, Mirko. Glass bond adhesive strength improvement by DCSBD atmospheric-pressure plasma treatment. International Journal of Adhesion and Adhesives [online]. 2017. vol. 78, pp. 1-3. [viewed 2019-09-01] Available from:

https://doi.org/10.1016/j.ijadhadh.2017.06.017

[3] HOMOLA, Tomáš, MATOUŠEK, Jindřich, KORMUNDA, Martin, WU, Linda Y. L., and ČERNÁK, Mirko. Plasma treatment of glass surfaces using diffuse coplanar surface barrier discharge in ambient air. Plasma Chemistry and Plasma Processing, [online]. 2013. vol. 33, iss. 5, pp. 881-894. [viewed 2019-09-16] Available from: https://doi.org/10.1007/s11090-013-9467-3

[4] YADAV, Brijesh Singh, BADGUJAR, Amol C., and DHAGE, Sanjay R. Effect of various surface treatments on adhesion strength of magnetron sputtered bi-layer Molybdenum thin films on soda lime glass substrate. Solar Energy, [online]. 2017. vol. 157, pp. 507-513. [viewed 2019-09-14] Available from:

https://doi.org/10.1016/j.solener.2017.08.068

[5] ŠTĚPÁNOVÁ, Vlasta, SLAVÍČEK, Pavel, VALTR, Miroslav, BURŠíKOVÁ, Vilma, and STUPAVSKÁ, Monika. Improvement of glass wetability using diffuse coplanar surface barrier discharge and gliding arc considerig aging effect. In Nanocon 2015 Proceedings. Brno, 2015, pp. 2-7. [viewed 2019-09-12] Available from: http://www.nanocon.eu/files/proceedings/23/papers/4546.pdf

[6] ČERNÁK, Mirko, ČERNÁKOVÁ, L, HUDEC, I., KOVÁČIK, Dušan, and ZAHORANOVÁ, Anna. Diffuse coplanar surface barrier discharge and its applications for in-line processing of low-added-value materials. EPJ Applied Physics, [online]. 2009. vol. 47, no. 2, p. 22806. [viewed 2019-09-07] Available from: https://doi.org/10.1051/epjap/2009131

[7] SIMON, Alpár, DINU, Otilia E., PAPIU, Mihaela A., TUDORAN, Cristian D., and ANGHEL, Sorin Dan. Ageing behavior of He DBD treated glass surface. Romanian Reports of Physics, [online]. 2012. vol. 57, iss. 9-10, pp. 1367-1374. [viewed 2019-09-12] Available from: http://www.nipne.ro/rip/2012 57 9-10/1367 1374.pdf.

[8] BUČEK, Andrej, HOMOLA, Tomáš, ARANYOSIOVÁ, Monika, VELIČ, Dušan, PLECENIK, Tomáš, HAVEL, Josef, SŤAHEL, Pavel, and ZAHORANOVÁ, Anna. Atmospheric pressure non-equilibrium plasma treatment of glass surface. Chemické Listy, [online]. 2008. vol. 102, pp. 1459-1462. [viewed 2019-09-12] Available from: http://www.chemicke-listy.cz/docs/full/2008 s4 s1459-s1462.pdf 